\title{
Technical Note: Technique for Dissection and Analysis of the Rumen in Young Calves
}

\author{
S. R. Hill, ${ }^{1}$ B. A. Hopkins, ${ }^{1}$ S. Davidson, ${ }^{1}$ S. M. Bolt, ${ }^{1}$ D. E. Diaz, ${ }^{1}$ C. Brownie, ${ }^{2}$ \\ T. Brown, ${ }^{3}$ G. B. Huntington, ${ }^{1}$ and L. W. Whitlow ${ }^{1}$ \\ ${ }^{1}$ Department of Animal Science, \\ ${ }^{2}$ Department of Statistics, and \\ ${ }^{3}$ College of Veterinary Medicine, North Carolina State University, Raleigh 27695
}

\section{ABSTRACT}

This paper discusses a technique used to evaluate rumen development in young calves, including removal, dissection, and analysis of tissue. The method allowed for examination of the different sacs of the rumen (dorsal, ventral, cranial, and caudal) using scanning electron microscopy to measure papillae denseness and histology slides to measure papillae length and width. Computer software was used to produce accurate measurements of papillae. The rumens of young calves were dissected, and samples were taken from the cranial, caudal, ventral, and dorsal sections. Calves were part of a nutrition research study, and dietary treatments did have an effect on development measurements such as length, width, and papillae denseness.

(Key words: calf, rumen, development, papilla)

Abbreviation key: $\mathbf{S A R}=$ surface area ratio, $\mathbf{S E M}=$ scanning electron microscopy.

To evaluate the effects of different ration ingredients on rumen development, techniques to remove, dissect, and analyze tissue can be used. A technique published by McGavin and Morrill (1976) was modified to use a different dissection pattern, different fixative, and updated microscopy techniques for tissue evaluation to include measurement of papillae. Papillae were evaluated using scanning electron microscopy (SEM) to measure papillae denseness and histology slides with the aid of computer software to accurately measure papillae length and width. Computer software was used to produce accurate measurements of papillae.

Twelve Holstein calves were euthanized with sodium pentobarbitol at $1 \mathrm{mg} / 4.5 \mathrm{~kg} \mathrm{BW}$ at $63 \mathrm{~d}$ of age by jugular venipuncture. These calves were part of a nutrition study conducted at the North Carolina State Uni-

Received August 29, 2003

Accepted July 23, 2004.

Corresponding author: B. A. Hopkins; e-mail: Brinton Hopkins@ncsu.edu. versity Dairy Education Unit and were dissected at the North Carolina State University College of Veterinary Medicine Necropsy Laboratory.

To remove the rumen, an incision was made along the ventral midline of the calf to expose the gastrointestinal tract. Once exposed, the tract was ligated at the cardiac sphincter and again at the pyloric sphincter and removed from the abdominal cavity. The tract was washed, and the exterior was photographed. The 4 sections of the rumen (cranial, caudal, dorsal, and ventral) were marked from the exterior while the rumen was positioned on its ventral side. The reticulum was removed, and an incision was made from the cardiac sphincter and continued in a lateral direction until the interior of the rumen was exposed. Rumen tissue was rinsed with cold water to remove the majority of contents and was photographed according to McGavin and Morrill (1976) (Figure 1). Five tissue samples (approx. $8 \times 4 \mathrm{~cm}$ ) were cut from each section of the rumen and stapled to wooden tongue depressors to prevent shrinkage in preservative (Figure 2). Because the method of dissection divided the dorsal section in half, tissue was sampled from both sides of the incision line. McGavin and Morrill (1976) recommended the separation of all sacs to completely examine the tissue through photography and to increase the ease of fixation. However, the technique used in this paper allows for all sacs of the rumen to remain attached and provides the opportunity to view the changes in rumen tissue in transitions to different sacs.

In contrast to McGavin and Morrill (1976), immediately after collection, samples were fixed in Trump's solution (McDowell and Trump, 1976), as opposed to formalin or $2.5 \%$ glutaraldehyde. Samples fixed in Trump's solution can be stained and processed by conventional means and embedded in paraffin blocks. Paraffin blocks made using tissue fixed in Trump's solution do not have the brittle characteristics of those made using tissue fixed in $2 \%$ or greater glutaraldehyde and have a longer storage period, up to several years. Samples were fixed in Trump's at a volume of 5 to 10 times the volume of the sample for $72 \mathrm{~h}$ minimum and then 


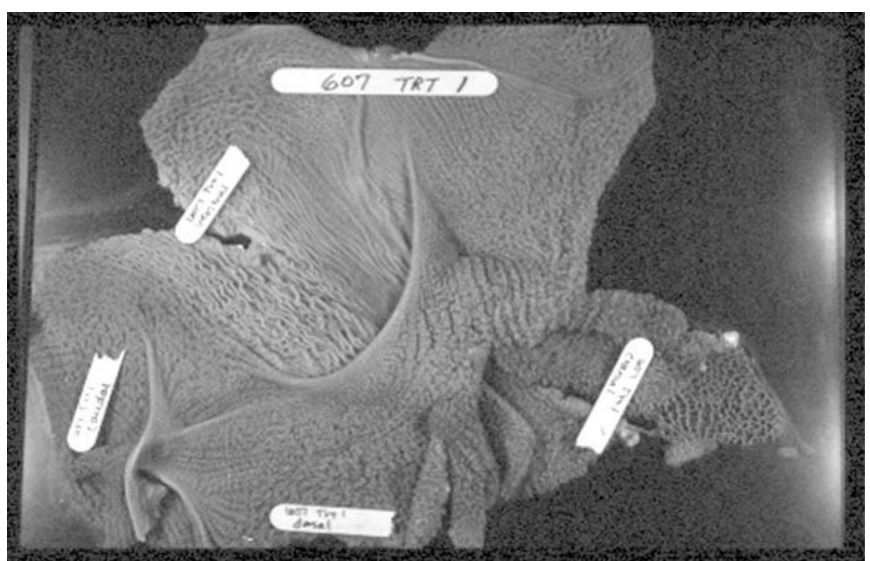

Figure 1. Interior rumen of calf dissected with sacs intact.

processed for evaluation with SEM for papillae denseness (Dykstra, 1993) and histology to determine papillae size (National Institutes of Health publication no. 80-275).

Histology slides were prepared at the North Carolina State University College of Veterinary Medicine Histopathology Laboratory. After the tissue was fixed in Trump's solution, it was trimmed of excess tissue and placed in a small tissue cassette. The tissue samples were processed on a Sakura Tissue Tek VIP processor (Sakura Finetek, Torrance, CA) overnight. This processor allows the samples to go through several alcohol dehydrations and be embedded in Formula R Paraffin. The Sakura Tissue Tek also cuts 5 - $\mu \mathrm{m}$ sections of the tissue using LEICA 2135 microtome and Tissue Tek high profile disposable knives. After the slides are dried,

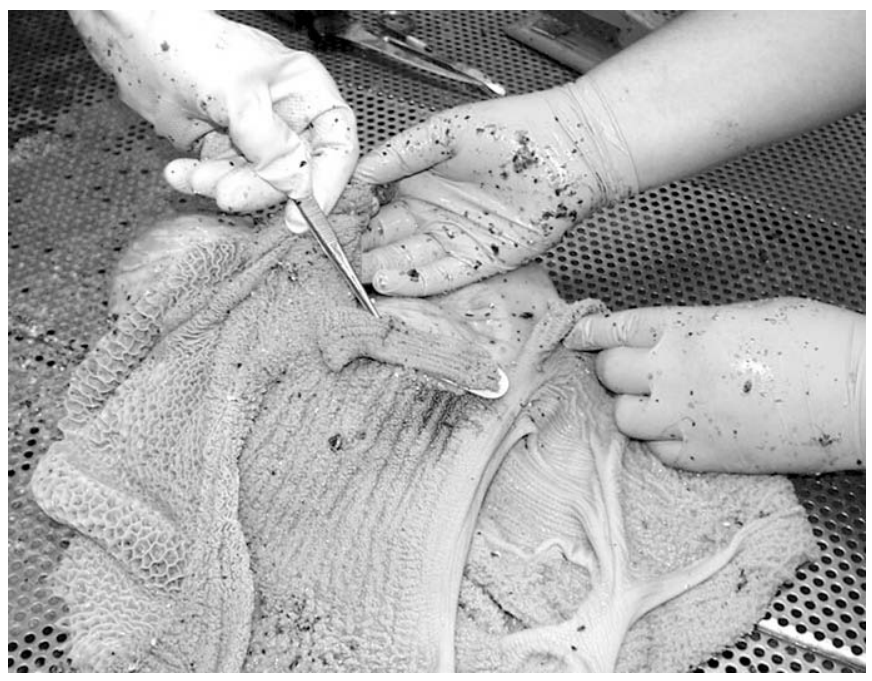

Figure 2. Tissue cut into small samples and stapled to tongue depressors.

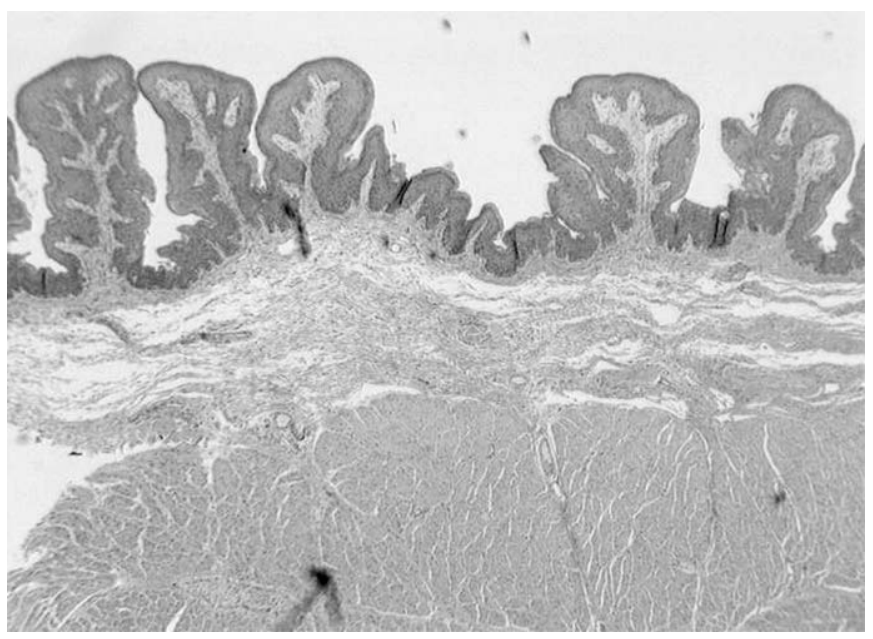

Figure 3. Example of histology slide used to measure papillae length and width.

they are stained on the Sakura 600 slide stainer using Mayer's-Harris hematoxylin mixture and Eosin stain. The slides are loaded into the racks of the Sakura 600 (Sakura Finetek), and the appropriate program is identified.

Using histology slides (Figure 3) and AxioVision 4.0 software (Carl Zeiss Vision Imaging System, Thornwood, NY), papillae length and width were measured and used to estimate surface area per $\mathrm{cm}^{2}$ of each rumen section. The length and width of papillae were determined using the AxioVision 4.0 software to trace and measure straight lines drawn across the length and width of each papilla. The lines representing the length started at the bases of the papillae and extended to the tips of the papillae. The lines representing the papillae width were drawn at the widest part and at a

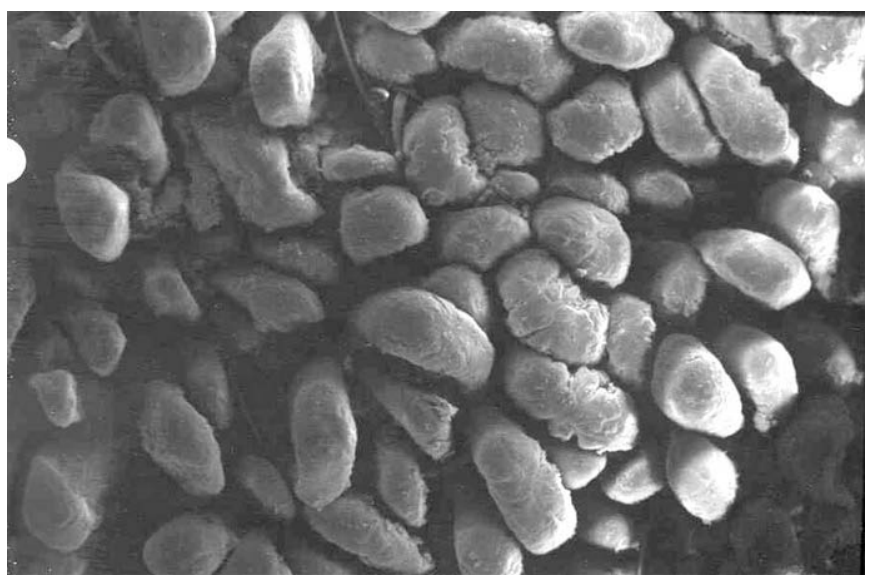

Figure 4. Example of scanning electron microscopy image used to measure papillae denseness. 
HILL ET AL.

Table 1. Differences in surface area ratio (SAR), papillae length, papillae width, and papillae denseness among cranial, caudal, ventral, and dorsal sections.

\begin{tabular}{|c|c|c|c|c|c|c|c|c|c|}
\hline \multirow[b]{2}{*}{ Variable } & \multicolumn{2}{|c|}{ Cranial } & \multicolumn{2}{|c|}{ Caudal } & \multicolumn{2}{|c|}{ Ventral } & \multicolumn{2}{|c|}{ Dorsal } & \multirow[b]{2}{*}{$P=$} \\
\hline & Mean & $\mathrm{SE}$ & Mean & $\mathrm{SE}$ & Mean & SE & Mean & SE & \\
\hline $\operatorname{SAR}\left(\mathrm{cm}^{2} / \mathrm{cm}^{2}\right)$ & 1.39 & 0.26 & 1.05 & 0.14 & 0.99 & 0.22 & 0.87 & 0.32 & 0.13 \\
\hline Papillae length $(\mathrm{mm})$ & 2.93 & 0.50 & 2.28 & 0.35 & 2.73 & 0.52 & 1.21 & 0.39 & 0.14 \\
\hline Papillae width (mm) & 0.36 & 0.02 & 0.36 & 0.02 & 0.40 & 0.02 & 0.33 & 0.02 & 0.19 \\
\hline Papillae denseness (no. per $\mathrm{cm}^{2}$ ) & $40.5^{\mathrm{ab}}$ & 4.6 & $40.0^{\mathrm{a}}$ & 3.6 & $31.7^{\mathrm{b}}$ & 1.7 & $57.6^{\mathrm{a}}$ & 9.6 & 0.04 \\
\hline
\end{tabular}

${ }^{a, b}$ Values within a row of means with different superscripts indicate significant differences $\left.(P<0.05)\right)$.

right angle to the lines representing length. Branches of papillae were measured as individual papillae in a similar manner. Denseness of papillae for each of the 5 samples from each of the 4 sections of the rumen was determined using digital images, acquired at $15 \mathrm{kV}$ from 20 to $30 \times$, from SEM (Figure 4). The images of each section were covered with acetate sheets, and each papilla was marked and counted.

Total estimated surface area of papillae of each section of the rumen was not measured; however, the assumption was made that the tissue samples accurately represented the entire section. Surface area of papillae per surface area of each ruminal section is presented as the surface area ratio (SAR) and was calculated using the following methodology. Papillae were considered to be cylindrical in shape with one closed end. Measured width was assumed equal to the diameter of the papillae. Therefore, equation 1 , used to calculate lateral area of papillae, was based on the surface area of a cylinder plus the area of a circle; equation 2 was used to calculate the average SAR of each section of the rumen by multiplying the average surface area of the papillae in each section by the average denseness or number of papillae per unit area in that section.

$$
\begin{gathered}
\text { Surface area of papillae }\left(\mathrm{cm}^{2}\right)= \\
\qquad 2 \times \mathrm{r} \times \pi \times \mathrm{L}+\pi \times \mathrm{r}^{2}
\end{gathered}
$$

where $\mathrm{r}=$ radius in $\mathrm{cm}$ and $\mathrm{L}=$ length in $\mathrm{cm}$.

$\begin{aligned} \mathrm{SAR} & =(\text { average surface area of papillae in section } \mathrm{X}) \\ & \times(\text { average papillae denseness in section } \mathrm{X})\end{aligned}$

where X can be cranial, caudal, ventral, or dorsal.

The Proc Mixed program of SAS was used to analyze papillae length, width, denseness, and the SAR within the rumen. The model included starter, supplement, and section with their interactions as fixed effects. Calf, nested in starter and supplement, was considered to be random. The different samples from each section of the rumen were thus considered to be a type of repeated measurement.

The least squares means of the SAR and papillae length, width, and denseness are reported in Table 1. Although there were no significant differences among sections for SAR, papillae length, or papillae width, density of papillae did vary among sections.

Many researchers have studied rumen development (Harrison et al., 1960; Stobo et al., 1966; McGavin and Morrill, 1976; Warner, 1991). The technique used in this study provides an efficient and accurate way to determine morphological and histological information about rumen papillae. The use of histology slides and scanning electron microscopy images coupled with computer software provides a modified technique to evaluate rumen development.

\section{REFERENCES}

Animal Histology Procedures of the Pathological Technology Section. 1979. NIH Publication no. 80-275, National Cancer Institute, Bethesda, MD.

Dykstra, M. J. 1993. A Manual of Applied Techniques for Biological Electron Microscopy. Plenum Press, New York, NY.

Harrison, H. N., R. G. Warner, E. G. Sandler, and J. K. Loosli. 1960 Changes in the tissue and volume of the stomachs of calves following the removal of dry feed or consumption of inert bulk. J. Dairy Sci. 43:1301-1312.

McDowell, E. M., and B. F. Trump. 1976. Histologic fixatives suitable for diagnostic light and electron microscopy. Arch. Pathol. Lab. Med. 100:405-414.

McGavin, M. D., and J. L. Morrill. 1976. Dissection technique for examination of the bovine ruminoreticulum. J. Anim. Sci. 42:535-538.

Stobo, I. J. F., J. H. B. Roy, and H. J. Gaston. 1966. Rumen development in the calf. 1 . The effects of diets containing different proportions of concentrates to hay on rumen development. Br. J. Nutr. 20:171-188.

Warner, R. G. 1991. Nutritional factors affecting the development of a functional ruminant-a historical perspective. Pages 1-12 in Proc. Cornell Nutr. Conf. Feed Manuf., Syracuse, NY. Cornell Univ., Ithaca, NY. 